14.10

\title{
Композитные матрицы на основе сополиамида и полипиррола для тканевой инженерии
}

\author{
(C) Н.В. Смирнова, ${ }^{1,2}$ И.Ю. Сапурина, ${ }^{1,2}$ М.А. Шишов, ${ }^{1,2}$ К.А. Колбе, ${ }^{1}$ Е.М. Иванькова, ${ }^{1,2}$ \\ B.B. Матреничев, ${ }^{2}$ B.E. Юдин ${ }^{1,2}$ \\ ${ }^{1}$ Санкт-Петербургский политехнический университет Петра Великого, \\ 195251 Санкт-Петербург, Россия \\ ${ }^{2}$ Институт высокомолекулярных соединений РАН, \\ 199004 Санкт-Петербург, Россия \\ e-mail: nvsmirnoff@yandex.ru
}

Поступило в Редакцию 4 февраля 2020 г.

В окончательной редакции 4 фревраля 2020 г.

Принято к публикации 17 февраля 2020 г.

\begin{abstract}
Продемонстрирована возможность применения электропроводящих полимеров для создания биоактивных матриц, предназначенных для тканевой инженерии. Среди них наиболее перспективным в контексте биомедицинского использования является полипиррол. Полипиррол обладает рядом свойств, которые делают его адекватной основой для создания „умных“ биоактивных материалов. Для достижения лучших механических свойств композиционных матриц использовали алифатический сополиамид. Из раствора сополиамида получены матрицы, имеющие структуру тонких пленок, а также волокнистых нетканых матов, изготовленных методом электроформования. Путем окислительной полимеризации пиррола сополиамидные пленки модифицированы полипирролом с образованием композитных матриц. Полученные образцы продемонстрировали адекватные применению эксплуатационные свойства и достаточный для клеточных технологий уровень электропроводности. В экспериментах in vitro матрицы на основе сополиамида и полипиррола поддерживают выживаемость, адгезию и пролиферацию дермальных фибробластов человека.
\end{abstract}

Ключевые слова: электропроводящие полимеры, полипиррол, матрица, тканевая инженерия.

DOI: $10.21883 /$ JTF.2020.10.49794.42-20

\section{Введение}

Современными исследованиями обоснована возможность применения электропроводящих полимеров (ЭП) в широком спектре биомедицинских технологий, к которым относится разработка систем доставки лекарственных препаратов, конструирование биосенсорных систем и биосовместимых электродов для применения in vivo и in vitro. Также продемонстрирована возможность применения ЭП для создания биоактивных матриц, предназначенных для клеточных технологий и тканевой инженерии [1]. При выборе материалов для регенеративных технологий электропроводящая полимерная матрица обладает оптимальными свойствами для доставки электрического сигнала к клеткам как in vitro, так и in vivo. Было показано, что экзогенные электрические стимулы оказывают влияние на фундаментальные аспекты жизнедеятельности и поведения клеток - адгезию, миграцию, пролиферацию. Под воздействием электростимуляции меняются также дифференцировочные приоритеты клеток [2]. Кроме клеток, которые традиционно считались электрочувствительными, в системах in vitro, in vivo и в некоторых клинических исследованиях была показана реакция дермальных фибробластов на электростимуляцию с целью улучшения заживления ран кожи и мягких тканей [3]. Кроме того, было показано, что электрические сигналы важны и на тканевом уровне, так, сохранение электрического потенциала между внешним и внутренними слоями кожи - важное условие для поддержания ее гомеостаза. В случае травмирования кожи или ее паталогических изменений заряд утекает, что негативно влияет на кожный метаболизм, темпы регенерации, а также может вызывать хронизацию ран [4].

ЭП представляют собой органические высокомолекулярные соединения. К наиболее изученным ЭП относятся полианилин, полиацетилен, полипиррол, политиофен, полифенилен, полифениленвинилен. Было показано, что электропроводность ЭП может достигать значений $10^{3}-10^{4} \mathrm{~S} \cdot \mathrm{cm}^{-1}$. В основе электропроводности полимеров наличие системы сопряженных химических связей. Внутримолекулярное строение ЭП предполагает возможность свободного перемещения заряда (электрона или дырки) вдоль полимерной цепи [5]. Это возможно, если атомы углерода полимерной цепи находятся в состоянии $s p^{2}$-гибридизации и располагаются на столь близком расстоянии друг от друга, что внешние орбиты электронов атомов углерода перекрываются. Дополнительными условиями являются допирование полимеров - процедура повышения концентрации носителей заряда в полимерном материале путем введения примесей органических или неорганических низкомолекулярных соединений [5], а также плотная упаковка полимерных цепей в надмолекулярные структуры. 


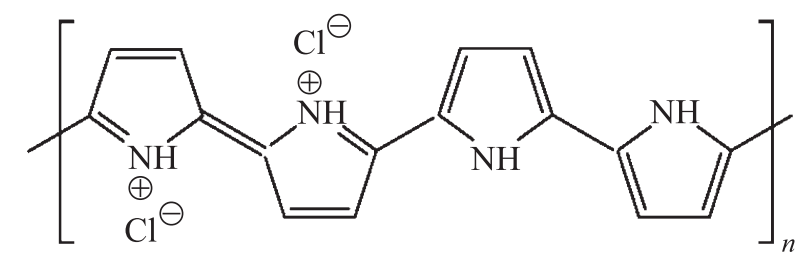

Рис. 1. Электропроводящая окисленная форма РРу, где носители заряда - положительные поляроны стабилизированы анионами хлора.

Наиболее перспективным ЭП в контексте биомедицинского использования является полипиррол (РРу) (рис. 1). Исследованию его свойств и возможностей применения посвящен большой массив публикаций [6]. РРу обладает окислительно-восстановительными свойствами, парамагнетизмом, его электронная и ионная проводимость чувствительна к внешним воздействиям, она контролируемо и обратимо изменяется в диапазоне $10^{-6}-10^{1} \mathrm{~S} \cdot \mathrm{cm}^{-1}$. Полимер биосовместим как in vitro, так и in vivo, химически стабилен на воздухе и воде и имеет достаточно высокую электропроводность в физиологических условиях. Это делают его перспективной основой для создания „умных“ биоактивных материалов [6].

РРу синтезируют методом окислительной полимеризации пиррола как химическим, так и электрохимическим способом. При химическом окислении используют широкий спектр окислителей и различные растворители, включая воду. Полимер синтезируют в виде наночастиц разной структуры, агрегированных в различные морфологические формы: от плотноупакованных до рыхлых, с большой площадью поверхности, и контролируемой пористостью. С целью адаптации к различным биомедицинским применениям РРу может быть модифицирован разными допирующими агентами, включая биоактивные молекулы. Свойства полимера можно обратимо менять с помощью наложения электрического потенциала [6].

РРу обычно используется в составе композиционных материалов, где второй компонент (компоненты) обеспечивает необходимые механические свойства материала (прочность, гибкость), отсутствующие у [7]. Однако получение таких композитов осложнено плохой перерабатываемостью РРу - отсутствием у полимера растворимости и плавкости, и невозможностью применения к РРу традиционных методов формования полимеров. Поэтому для получения композитов чаще всего используют метод in situ полимеризации, который объединяет в одну стадию синтез РРу и формирование композита. Синтез проводится in situ, т. е. в присутствии второго компонента, выполняющего функцию носителя. При этом в ходе полимеризации РРу сорбируется на носитель в виде нанослоя, покрывает его поверхность и внедряется в поры. Методика получения каждого композита разрабатывается индивидуально, поскольку свойства РРу, а также толщина однородность и структура полимерного слоя очень чувствительны к природе носителя и условиям синтеза [6].

В настоящей работе получены и исследованы композиционные матрицы на основе РРу и сополимера алифатического полиамида (SPA, сополимер $\varepsilon$-капролактама с полигексаметиленадипинамидом). SPA обладает хорошими механическими свойствами и высокой стабильностью. Он устойчив к воздействию углеводородов, кетонов, эфиров, масел и щелочей, обладает хорошими пленко- и волокнообразующими свойствами. Материалы из этого полимера сохраняют свои эксплуатационные характеристики в водных средах в течение длительного времени. Кроме того, SPA биологически инертен, из-за отсутствия остатков растворителя и других токсичных примесей, что позволяет использовать его для получения материалов медицинского назначения. Композиционные материалы на основе нановолокон из SPA и нановолокон хитозана применяют в качестве эффективного раневого покрытия, которое способствует высокой скоростью заживления глубоких поражений покровной ткани человека или животного [8].

В настоящей работе представлен синтез композита SPA и РРу в виде двух типов материалов: сплошной пленки (SPA-PРy) и пористого электроформованного мата (e-SPA-PPy). Изучены морфология и электропроводность полученных образцов. С помощью культуры дермальных фибробластов человека показана их биосовместимость.

\section{1. Материалы и методы}

\section{1. Материалы}

Использовали гранулированный полимерный материал марки ПА 6/66-3 (ООО „АНИД““, Россия), который представляет собой сополимер $\varepsilon$-капролактама $\left[-\mathrm{NH}-\left(\mathrm{CH}_{2}\right)_{5}-\mathrm{CO}-\right]_{n}$ и соли адипиновой кислоты $\left[-\mathrm{NH}-\left(\mathrm{CH}_{2}\right)_{6}-\mathrm{NH}-\mathrm{CO}-\left(\mathrm{CH}_{2}\right)_{4}-\mathrm{CO}-\right]_{n}(\mathrm{SPA})$ с соотношением компонентов 40:60, молекулярной массой $M_{w}=30 \mathrm{kDa}$ и температурой плавления $T_{m}=188^{\circ} \mathrm{C}$.

Раствор, содержащий 18 mass.\% $\quad$ SPA в смеси этанол/вода $=80 / 20 \mathrm{vol} . \%$ готовили в течение $3 \mathrm{~h}$ при температуре $60^{\circ} \mathrm{C}$ и интенсивном перемешивании. Затем раствор фильтровали и удаляли растворенные в нем газы при давлении $0.1 \mathrm{~atm}$. в течение $2 \mathrm{~h}$.

Сплошные пленки SPA отливали из спиртового раствора и высушивали на стекле при комнатной температуре и влажности, при этом толщина пленки составляла порядка $10 \mu \mathrm{m}$.

Электроформование волокон производили на лабораторной установке „Nanon-01A“ (Япония). Полученный раствор помещали в электрод-фильеру диаметром $1.2 \cdot 10^{-3} \mathrm{~m}$ и подавали в электрическое поле напряженностью $E=1.4-2.0 \cdot 10^{5} \mathrm{~V} \cdot \mathrm{m}^{-1}$ при расстоянии между электродами 0.1-0.2 m, скорость подачи растворов составляла $Q=28-70 \cdot 10^{-5} \mathrm{~cm}^{3} / \mathrm{s}$. Осаждение волокон с 
формированием нетканого мата происходило на приемный электрод, который представлял собой металлическую пластину.

\section{2. Метод модификации образцов полипирролом}

Образцы нетканого электроформованного материала размерами $5 \times 10 \mathrm{~cm}$, закрепленные в растянутом состоянии на каркасе, погружали в водный раствор окислителя - треххлористого железа с концентрацией $0.1 \mathrm{M}$. После обработки окислителем и кратковременного подсушивания образец переносили в подкисленный $0.1 \mathrm{M}$ соляной кислотой раствор пиррола (Sigma-Aldridge) с концентрацией $0.05 \mathrm{M}$. Окислительная полимеризация пиррола протекала при температуре $4^{\circ} \mathrm{C}$ без перемешивания в течение $6 \mathrm{~h}$. Модифицированные РРу, и получившие черную окраску образцы, многократно промывали дистиллированной водой и сушили на воздухе в растянутом на каркасе состоянии в течение суток.

\section{3. Изучение морфологии образцов}

Для исследования структуры полученных нетканых материалов использовали сканирующий электронный микроскоп Carl Zeiss Supra 55 VP, фирмы Carl Zeiss (Германия). Перед исследованием на установке EikoIB3 (Ioncoater) на образцы SPA и e-SPA напыляли слой золота толщиной $\sim 25 \mathrm{~nm}$ при ионном токе $6 \mathrm{~mA}$ и межэлектродном напряжении $1.5 \mathrm{kV}$. Образцы композиционных материалов SPA-PРу и е-SPA-PРу исследовали без напыления золота, поскольку они обладали необходимой электропроводностью.

\section{4. Оценка электропроводности материалов}

Поверхностное сопротивление образцов SPA и е-SPA измеряли до и после модификации их РРу в соответствии с тестовой методикой ААТСС 76-2005 [9]. Измерительное прижимное устройство состояло из двух платиновых полос длиной $10 \mathrm{~mm}$, закрепленных в тефлоновом держателе параллельно друг другу на расстоянии $10 \mathrm{~mm}$. Устройство накладывалось на образец и прижималось массой $1 \mathrm{~kg}$. Измерение каждого образца с обеих сторон проводилось 5 раз, после чего вычислялся среднеарифметический результат. Поверхностное сопротивление рассчитывалось по формуле: $R_{s}=R \cdot l / w$, где $R_{s}$ поверхностное сопротивление, $[\Omega / \mathrm{sq}], R-$ сопротивление, $[\Omega], l$ - длина электродов, $w-$ расстояние между электродами. Измерения проводили при комнатной температуре на сухих образцах (высушены до постоянного веса при комнатной температуре и влажности), а также на образцах, смоченных физиологическим раствором $(10 \% \mathrm{NaCl})$.

Удельное электрическое сопротивление РРу, полученного в тех же экспериментальных условиях, определя- лось четырехточечным методом на образцах, спрессованных в виде таблеток.

Измерения проводились с использованием вольтметра-амперметра Keithley 2010 и источника тока Keithley 237.

\section{5. Исследование биосовместимости материалов}

Исследование биосовместимости проводили на композитах SPA-PРy и e-SPA-PРy, многократно промытых физиологическим раствором с нейтральным $\mathrm{pH}$.

\section{6. Культивирование клеток}

Для проведения исследований использовали штамм фибробластов кожи условно здорового донора, полученный из коллекции клеточных культур Института цитологии РАН (Санкт-Петербург). Клетки культивировали в полной питательной среде ДМЕМ (Панэко, Россия) с добавлением 1\% L-глютамина $200 \mathrm{mM}, 10 \%$ бычьей эмбриональной сыворотки и $1 \%$ антибиотиков $(100 \mathrm{un} . / \mathrm{mL}$ пенициллин, $100 \mu \mathrm{g} / \mathrm{mL}$ стрептомицин), $1 \%$ антимикотика (амфотерицин В $250 \mu \mathrm{g} / \mathrm{mL}$ ) (все рективы Gibco, CША). Культивирование проводили в $\mathrm{CO}_{2}$ инкубаторе (Thermo Fisher Scientific, США) при темпратуре $37^{\circ} \mathrm{C}$, концентрации $\mathrm{CO}_{2} 5 \%$ и повышенной влажности. Для проведения исследований использовали клетки до 15 пассажа.

\section{7. МТТ-тест для определения количества жизнеспособных клеток}

Экспериментальные образцы пленок дезинфицировали, нарезали круглыми фрагментами по размеру лунки 24 луночного культурального планшета и помещали в лунки. В лунки добавляли суспензию клеток в полной культуральной среде, содержащую 25 тыс. клеток. Проводили инкубацию клеток в течение необходимых промежутков времени (3 суток) Заменяли ростовую среду на раствор МТТ (тиазолиловый синий тетразолийбромид) (Thermo Fisher Scientific, США) и инкубировали образцы 2 h. Удаляли раствор, а образовавшиеся кристаллы формазана экстрагировали, добавляя в лунки диметилсульфоксид. Тщательно перемешав получившийся раствор семплером, разаликвочивали его по лункам 96 луночного культурального планшета. Регистрировали оптическую плотность раствора с использованием спектрофотометра SPECTROstar Nano на длине волны $570 \mathrm{~nm}$. Оптическая плотность коррелирует с количеством жизнеспособных клеток.

\section{2. Результаты и обсуждение}

Синтез композитов SPA-PРy и e-SPA-PPy осуществляли с использованием сплошной и электроформованной пленки SPA методом in situ полимеризации 


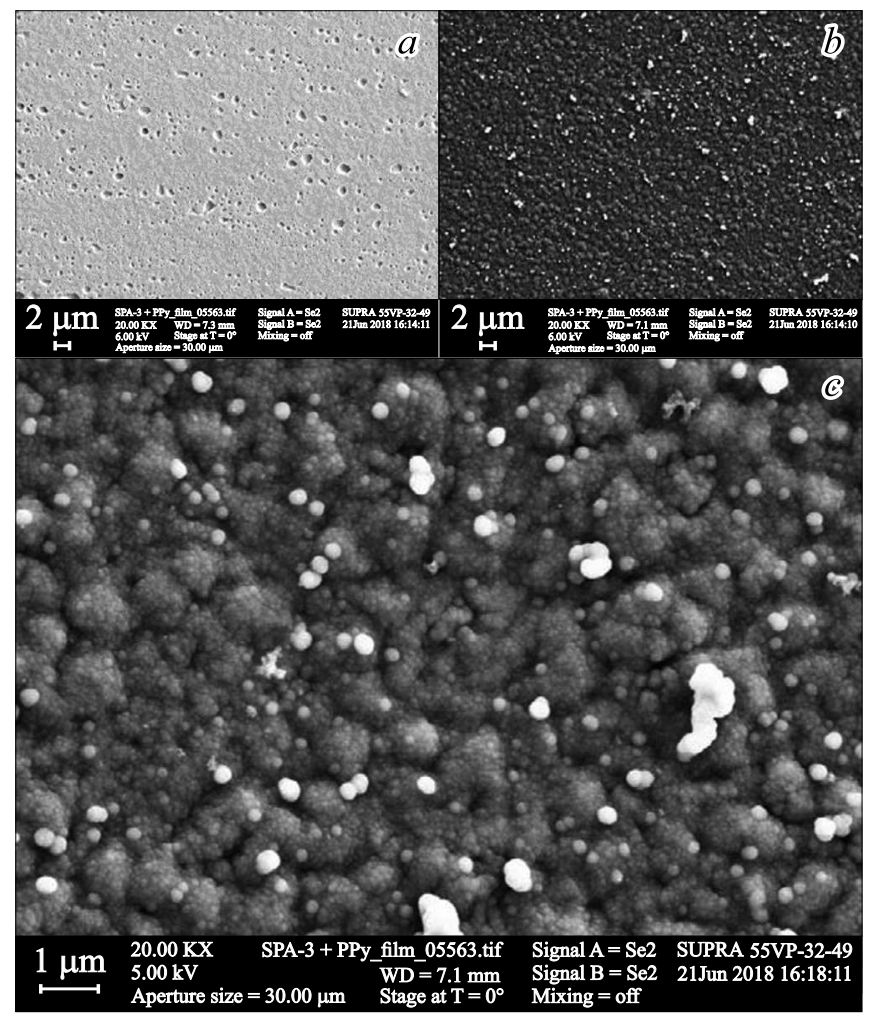

Рис. 2. SEM микрофотография поверхности сплошных пленок: $a-\mathrm{SPA}, b-\mathrm{SPA}-\mathrm{PPy}, c-\mathrm{SPA}-\mathrm{PPy} \mathrm{при} \mathrm{большем}$ увеличении.

пиррола на носителе, погруженном в реакционную среду. В присутствии носителя в виде пленки SPA синтез РРу может идти как в объеме реакционной среды, так и гетерофазно, непосредстенно на поверхности носителя с образованием нанослоя РРу. Вклад „объемной“ и „поверхностной“ реакций зависит от множества факторов, основными являются взаимодействие пиррола и интермедиатов его окислительной полимеризации с поверхностью носителя, а также смачиваемость SPA. Слой, формируемый на поверхности, имеет, как правило, хорошую адгезию к носителю, а РРу, полученный в результате „объемной“ реакции не имеет адгезии и может удаляться при промывке модифицируемого материала. В ходе синтеза РРу формируется в виде окисленной электропроводящей формы. Однако электропроводность самого РРу зависит от условий полимеризации и требует контроля, который удобно проводить либо на РРу, полученном в тех же условиях, но без носителя, либо на РРу, сформированном в результате „объемной“ реакции и отмытом от носителя.

Образцы SPA, полученные путем заливки раствора полимера на стекло, представляют собой пленки с незначительной бугристостью на поверхности (рис. 2,a). После модификации РРу основа покрывается сплошным слоем электропроводящего полимера (рис. 2,b). При большем увеличении видно, что слой РРу состоит из плотноупакованных частиц сферической формы диаметром примерно $100 \mathrm{~nm}$ (рис. 2,c). Это типичная картина in situ формирования монослоя наночастиц РРу в результате нуклеации поверхности носителя с последующим гетерофазным ростом полимерных цепей на интерфейсе пленка/раствор. Поскольку частицы РРу имеют сферическую форму, можно приблизительно оценить толщину слоя РРу, которая равна диаметру наночастицы и составляет 100-150 nm. В образцах практически отсутствует РРy, не связанный с поверхностью SPA.

Образец, полученный методом электроформования, состоит из однородных по длине волокон SPA диаметром от 100 до $500 \mathrm{~nm}$ с гладкой поверхностью. Волокна формируют высокопористый мат с порами микронных размеров (рис. 3,a). После модификации полипирролом общая структура волокнистой пористой матрицы сохраняется (рис. $3, b$ ). На изображении общего плана видны индивидуальные волокна и пористая структура электроформованной матрицы, однако поверхность волокон меняется. Волокна покрыты сплошным слоем РРу, а места перекрестья волокон ,заплыли и срослись“. При большем увеличении видно, что слой РРу состоит из плотноупакованных частиц сферической формы диаметром 50-70 nm (рис. 3,c). В образцах практически отсутствует РРу не связанный с поверхностью SPA. Лишь небольшое количество сферических частиц „свободного“ РРу можно найти на изображении.

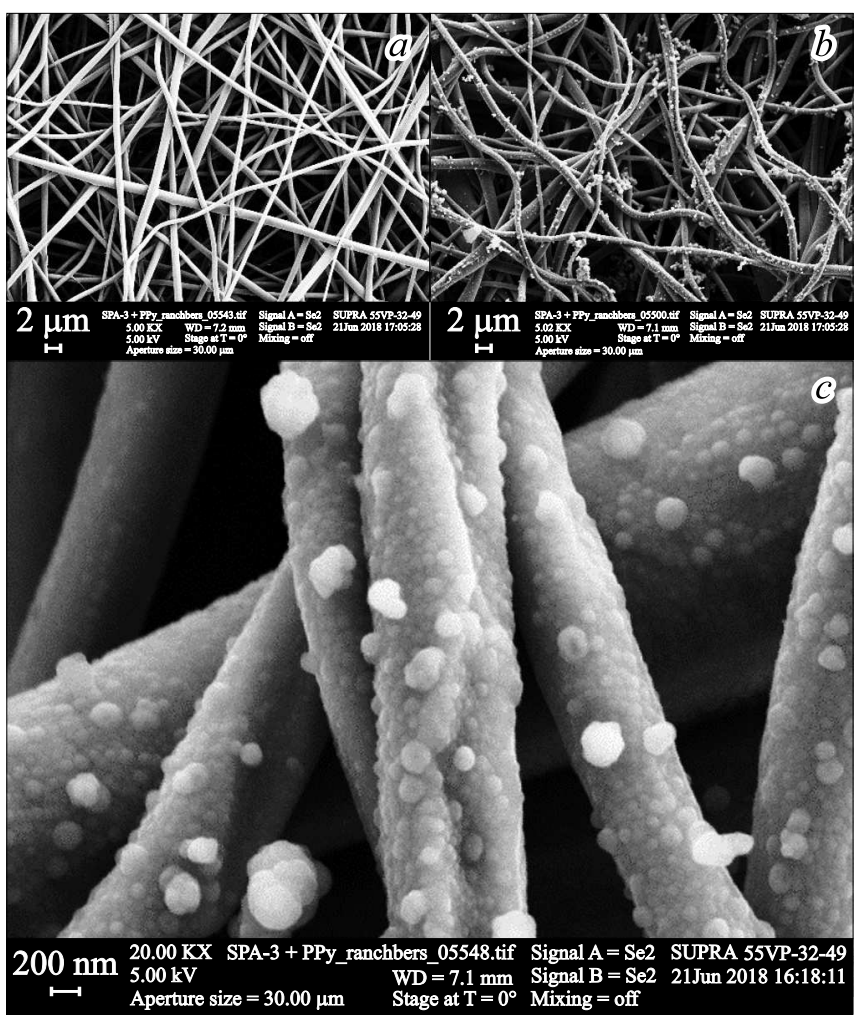

Рис. 3. SEM микрофотография полученных электроформованием пленок: $a-\mathrm{e}-\mathrm{SPA}, b-\mathrm{e}-\mathrm{SPA}-\mathrm{PPy}, c-\mathrm{e}-\mathrm{SPA}-\mathrm{PPy}$ при большем увеличении. 
Поверхностное $\left(R_{s}\right)$ и объемное $\left(R_{v}\right)$ сопротивление материалов в условиях различной влажности и кислотности

\begin{tabular}{c|c|c|c|c}
\hline \multirow{2}{*}{ Образец } & $\begin{array}{c}\text { Условия } \\
\text { кислотн- } \\
\text { ности, } \mathrm{pH}\end{array}$ & $\begin{array}{c}\text { Состояние } \\
\text { образца }\end{array}$ & $R_{s}, \mathrm{k} \Omega / \mathrm{sq}$ & $R_{v}, \Omega \cdot \mathrm{ma}$ \\
\hline \multirow{2}{*}{ РРу } & 2.5 & сухой & $0.01 \pm 0.001$ & $0.01 \pm 0.001$ \\
\cline { 2 - 5 } & 6.8 & сухой & $0.18 \pm 0.020$ & $0.20 \pm 0.02$ \\
\hline \multirow{3}{*}{ SPA-PРy } & 2.5 & сухой & $0.3 \pm 0.050$ & \\
\cline { 2 - 5 } & 6.8 & сухой & $7.0 \pm 0.14$ & $1.4 \pm 0.3$ \\
\cline { 2 - 5 } & 6.8 & влажный & $3.0 \pm 0.10$ & \\
\hline \multirow{3}{*}{ e-SPA-РРу } & 2.5 & сухой & $0.4 \pm 0.17$ & \\
\cline { 2 - 5 } & 6.8 & сухой & $9.0 \pm 3.60$ & \\
\cline { 2 - 5 } & 6.8 & влажный & $5.0 \pm 2.00$ & \multicolumn{1}{|c}{} \\
& & &
\end{tabular}

В таблице представлены данные по электропроводности исходных пленок SPA и е-SPA, композитов SPA-PРу и е-SPA-PPy, а также образцов РPy, спрессованных в виде таблеток. Сопротивление пленок SPA и e-SPA выше $600 \mathrm{M} \Omega / \mathrm{sq}$, что превышает диапазон возможных измерений и свидетельствует о высоких диэлектрических свойствах SPA. Известно, что алифатические полиамиды используются в качестве изоляторов в электротехнических конструкциях, их удельное сопротивление составляет от $10^{12}$ до $10^{15} \Omega \cdot \mathrm{m}$ [10]. После модификации РРу поверхностное сопротивление пленок значительно снижается. Наиболее низкое сопротивление имеют пленки непосредственно после синтеза, который осуществляется в кислой среде $(\mathrm{pH}<3)$. При $\mathrm{pH} 2.5$ РРу полностью допирован присутствующей в реакционной среде кислотой и его электропроводность максимальна. После промывки образцов дистиллированной водой и далее физиологическим раствором ( $\mathrm{pH} 6.8$ ) их электропроводность снижается более чем на порядок, вследствие частичной депротонации РРу и уменьшении количества носителей заряда. Эти изменения демонстрирует как исходный РРу, так и пленочные композиты SPA-PРy и e-SPA-PРу. При увлажнении физиологическим раствором электропроводность SPA-PРу и e-SPA-PРу повышается примерно вдвое, что объясняется добавочным вкладом ионной проводимости водного электролита. Погрешность кондуктометрических измерений $\mathrm{e}-\mathrm{SPA}-\mathrm{PPy}$ достигает $40 \%$, что значительно выше, чем измерений сплошных пленочных образцов (до 20\%) и тем более прессованных образцов (10\%). Это связано с неоднородностью плотности и толщины электроформованной матрицы на различных участках. При длительном пребывании на воздухе и в физиологическом растворе образцы стабильны и не снижают электропроводность. Таким образом, сопротивление образцов SPA, модифицированных РРу, не превышает $15 \mathrm{k} \Omega / \mathrm{sq}$ даже при нейтральном рН 6.8 в физиологиче- ских условиях, которые благоприятны для роста клеток. Данный уровень электропроводности вполне приемлем для проведения электрических измерений и электростимуляции клеток и тканей.

С использованием культуры дермальных фибробластов человека было показано, что включение в состав композита РРу не вызывает цитотоксического действия на культуру клеток. Кроме того, в сравнении со сплошными пленками из SPA-PРy, нетканые маты на основе e-SPA-PРу лучше поддерживают адгезию и пролиферацию фибробластов. Результаты зарегистрированы на 3 сутки культивирования (рис. 4).

Таким образом, композиционные матрицы, имеющие в своем составе полимер, обеспечивающий необходимые механические свойства и электропроводящий полимер, могут выполнять ряд задач в области современных регенеративных технологий. Во-первых, это транслирование электрического сигнала в системах „матрица-клетка“ и „раневое покрытие-ткань“, во-вторых, матрицы подобного типа могут стабилизировать предварительно посеянные клетки, что важно для доставки цитокинов и коллагена в ложе раны, в-третьих, уникальные свойства РРу делают возможным также сорбцию белков плазмы крови, доставку и контролируемое высвобождение биоактивных молекул, что дополнительно способствует ускорению процесса заживления. При этом волокнистая структура матрицы увеличивает ее ценность не только за счет возрастания отношения поверхности к объему и, следовательно, количества загруженных молекул и клеток. Пористая волокнистая топография матрицы обеспечивает значительные преимущества для клеточных культур, поскольку вызывает рост активности клеток по сравнению с плоскими поверхностями, состоящими из тех же материалов [11]. Из вышесказанного очевидно, что волокнистая матрица, изготовленная из электроактивного полимерного композита, может быть с успехом использована для различных регенеративных технологий, применяемых для лечения травм кожи и мягких тканей.

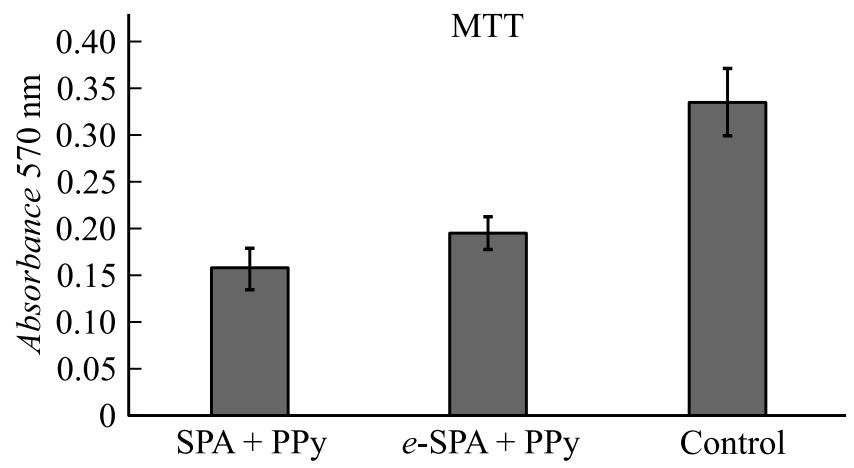

Рис. 4. Данные МТТ теста по оценке цитотоксического и регулирующего пролиферативную активность действия матриц на основе SPA-PРу и е-SPA-PРу на культуру дермальных фибробластов человека. 


\section{Финансирование работы}

Финансирование исследований, представленных в работе, осуществлялось из средств гранта № 19-73-30003 Российского научного фонда.

\section{Благодарности}

Авторы благодарят Российский научный фонд за поддержку исследований в рамках гранта № 19-73-30003.

\section{Конфликт интересов}

Авторы заявляют, что у них нет конфликта интересов.

\section{Список литературы}

[1] Nezakati T., Seifalian A., Tan A., Seifalian A. M. // Chem. Rev. 2018. Vol. 118. N 14. P. 6766-6843.

DOI: $10.1021 /$ acs.chemrev.6b00275

[2] Whited J.L., Levin M. // Current Opinion in Genetics \& Development. 2019. Vol. 57. P. 61-69. https://doi.org/10.1016/j.gde.2019.06.014

[3] Hunckler J., de Mel A. // J. Multidisciplinary Healthcare. 2017. Vol. 10. P. 179-194. DOI: 10.2147/JMDH.S127207

[4] Foulds I.S., Barker A.T. // Br. J. Dermatol. 1983. Vol. 109. N 5. P. $515-522$. https://doi.org/10.1111/j.1365-2133.1983.tb07673.x

[5] Balint R., Cassidy N.J., Cartmell S.H. // Acta Biomater. 2014. Vol. 10. N 6. P. 2341-2353. DOI: 10.1016/j.actbio.2014.02.015

[6] Ateh D., Navsaria H., Vadgama P. // J. R. Soc. Interface. 2006. Vol. 3. P. 741-752. DOI: 10.1098/rsif.2006.0141

[7] Martin D.C. // MRS Commun. 2015. Vol. 5. P. 131-153. DOI: https://doi.org/10.1557/mrc.2015.17

[8] Смирнова Н.В., Петрова Н.О., Лебедева И.О., Попрядухин П.В., Добровольская И.П., Юдин В.Е. // Научнотехнические ведомости СПбГПУ. Физико-математические науки. 2016. № 4(253). С. 129-138.

[9] AATCC Test Method 76-2005, „Electrical Surface Resistivity of Fabrics“'. AATCC Technical Manual. 2010. Vol. 85. P. 97.

[10] Liu J.-Y., Kou-Bing C., Hwang J.-F., Liu J.-Y., Kou-Bing C., Hwang J.F., Lee M.H. // J. Ind. Text. 2011. Vol. 41. P. 123.

[11] Xu X, Liu R., Li L. // Chem. Commun. 2015. Vol. 51. P. 16733. 